\title{
PIF-Mediated Sucrose Regulation of the Circadian Oscillator is Light Quality and Temperature Dependent
}

\author{
Ekaterina Shor ${ }^{1} \oplus$, Raya Potavskaya ${ }^{1}$, Ayelet Kurtz ${ }^{1}$, Inyup Paik ${ }^{2}$, Enamul Huq ${ }^{2}{ }^{\oplus}$ and \\ Rachel Green $1, *$ (D) \\ 1 Department of Plant and Environmental Sciences, Institute for Life Sciences, Edmond J. Safra Campus, \\ Givat Ram, Hebrew University, Jerusalem, 91904 Israel; ekaterin.shor@mail.huji.ac.il (E.S.); \\ poltavskaya.raya@gmail.com (R.P.); ayelet.kurtz@mail.huji.ac.il (A.K.) \\ 2 Department of Molecular Biosciences and The Institute for Cellular and Molecular Biology, \\ The University of Texas at Austin, Austin, TX 78712, USA; inyuppaik@gmail.com (I.P.); \\ huq@austin.utexas.edu (E.H.) \\ * Correspondence: rgreen@mail.huji.ac.il; Tel.: +972-2-6585391
}

Received: 19 October 2018; Accepted: 10 December 2018; Published: 13 December 2018

\begin{abstract}
Studies are increasingly showing that metabolic and circadian $(\sim 24 \mathrm{~h})$ pathways are strongly interconnected, with the circadian system regulating the metabolic state of the cell, and metabolic products feeding back to entrain the oscillator. In plants, probably the most significant impact of the circadian system on metabolism is in its reciprocal regulation of photosynthesis; however, the pathways by which this occurs are still poorly understood. We have previously shown that members of the basic helix-loop-helix (bHLH) transcription factor PHYTOCHROME INTERACTING FACTOR (PIF) family are involved in the photosynthate entrainment of the circadian oscillator. In this paper, using Arabidopsis mutants and overexpression lines, we examine how temperature and light quality affect PIF-mediated sucrose signaling to the oscillator and examine the contributions of individual PIF members. Our results also show that the quality of light is important for PIF signaling, with red and blue lights having the opposite effects, and that temperature affects PIF-mediated sucrose signaling. We propose the light sensitivity of PIF-mediated sucrose entrainment of the oscillator may be important in enabling plants to distinguish between sucrose produced de novo from photosynthesis during the day and the sucrose products of starch degradation at the end of the night.
\end{abstract}

Keywords: circadian rhythms; sucrose signal; PIFs; red/blue ratio; temperature

\section{Introduction}

Circadian, $\sim 24 \mathrm{~h}$ endogenous time-keeping systems, enable plants to anticipate and adapt to day/night and seasonal changes in their environment. At the core of the system is the oscillator that generates the rhythms. In Arabidopsis, the circadian oscillator consists of a series of interlocking feedback loops, in which components regulate each other on different levels. A central loop comprises transcription factors that regulate each other's expression. Products of CIRCADIAN CLOCK ASSOCIATED 1 (CCA1) and LATE ELONGATED HYPOCOTYL (LHY), whose expression peaks at dawn, affect the expression of daytime-active genes PSEUDO-RESPONSE REGULATORs (PRRs), evening-phased genes-(TOC1, GIGANTEA (GI), and elements of the evening complex (EC): LUX ARRHYTHMO (LUX) and EARLY FLOWERING 3/4 (ELF3/4). Expression of CCA1 and LHY is, in turn, repressed by TOC1 and PRRs) [1-3]. PRRs also repress the expression of REVEILLE8 
(RVE8) [4]. Other members of the REVEILLE family of transcription factors are, partially redundantly, involved in control of the clock pace [5]. Post-transcriptionally, the oscillator is regulated by alternative splicing and the control of mRNA stability [6-8]. On post-translational level, oscillator function is shown to be regulated by a time-dependent control of PRR5 and TOC1 protein degradation $[9,10]$. Among numerous biological processes regulated by the circadian oscillator in plants are scent production, defense responses, photosynthetic capacity and hormone production, and the control of photoperiodic responses such as flowering [3,11]. Moreover, even though circadian oscillators are extremely robust, they are adjustable and entrained by the environment.

In the natural world, both light and temperature change throughout the day: for example, cooler nights and warmer days, or low levels of blue-enriched light just before sunrise, compared to red-enriched light during the day. Both temperature and light affect the oscillator. Not surprisingly, given the importance of accurate circadian timing, the plant circadian system is extremely sensitive to light quality and quantity, either perceived directly, via photoreceptors, or indirectly, via photosynthetic products, the most important one being sucrose. Such multi-faceted entrainment may ensure that photosynthesis, one of the most important processes regulated by the circadian oscillator, is optimized at the same time as other circadian-controlled processes are correctly regulated $[3,12]$.

Several recent studies have focused on understanding how photosynthates entrain the oscillator. The oscillator components PRR7 and GI have been shown to be involved in distinct sucrose signaling pathways $[13,14]$. In the dark, metabolizable sugars stabilize GI protein. During the day, repression of PRR7 modulates CCA1 expression to adjust the phase of the oscillator; exogenous sucrose shortens the circadian period in wild type but not in prr7-11 or cca1-11 mutants. By contrast, in the dark, mutations CCA1 and PRR7 do not affect sucrose responsiveness of the oscillator. A bZIP family of transcription factor called bZIP63 also directly controls the expression of $P R R 7$ and mediates sucrose signaling to the oscillator [15]. In previous work, we established that the photosynthate entrainment of the oscillator is also mediated by members of the bHLH transcription factor PHYTOCHROME INTERACTING FACTOR (PIF) family [16,17]. In Arabidopsis, the PIF family comprises seven members (PIF1, PIF3-8), and we have shown that a higher order, quadruple (pif1, pif3, pif4 and pif5) mutant (pifQ) has longer period rhythms in response to exogenous sucrose in a range of red light intensities from 1-75 $\mu \mathrm{mol}$ $\mathrm{m}^{-2} \mathrm{~s}^{-1}$ as well as in white light and in the dark. Our results also demonstrated that PIFs show sucrose-dependent binding to the promoters of CCA1 and $L H Y$, but not $P R R 7$, at subjective dawn [16] and we suggested that this binding directly affects circadian timing.

In this paper, we further explore how the PIF-mediated sucrose entrainment of the oscillator is dependent on light quality and the roles of individual PIFs. Many studies have shown that PIFs can act as hubs in signaling pathways from diverse environmental signals including changes in temperature. For example, flowering time acceleration by increasing temperature is mediated by PIF4 [18] and we show how temperature affects PIF-regulated sucrose entrainment of the oscillator.

\section{Materials and Methods}

\subsection{Plant Materials and Growth Conditions}

The Arabidopsis (Arabidopsis thaliana) ecotype Columbia-0 (Col-0) was used as the background for all the experimental lines. pifQ (pif1pif3pif4pif5), pifQ CCA1:LUCIFERASE (LUC) and wild-type (wt) CCA1:LUC transgenic plants are described in [16,19]. The PIF- overexpression (PIF-ox) lines used were 35spro:PIF1-HA [20], 35spro:PIF3-myc [21], 35spro:PIF4-myc and 35spro:PIF5-myc [22]. For all experiments, seeds were imbibed and cold-treated at $4{ }^{\circ} \mathrm{C}$ for 4 days and sown onto Petri dishes with Murashige and Skoog (MS) medium (Duchefa Biochemie, Netherlands) with or without 3\% $(w / v)$ sucrose (for luciferase assay), or $2 \%$ sucrose $(w / v)$ (for leaf movement assays and RT-PCR). Unless otherwise stated, plants were grown in $14 \mathrm{~h}$ light: $10 \mathrm{~h}$ dark (14 L:10 D) with $100 \mu \mathrm{mol} \mathrm{m} \mathrm{m}^{-2} \mathrm{~s}^{-1}$ white light supplied by Philips fluorescent lights TLD $18 \mathrm{~W} / 840$ at $23^{\circ} \mathrm{C}$. 


\subsection{Bioluminescence Assays}

For the circadian bioluminescence assays, 6-8 seedlings from each of 3-4 independent lines carrying the CCA1:LUCIFERASE (CCA1:LUC) reporter (pifQ CCA1:LUC and wt CCA1:LUC) were grown for 8 days in $14 \mathrm{~L}: 10 \mathrm{D}$. After spraying with 2.5mM luciferin (D-Luciferin, Potassium salt, Gold Biotechnology, St Louis, MO, USA) in $0.01 \%$ Triton X-100, the seedlings were transferred to a growth chamber mounted with a Hamamatsu ORCA II ER CCD camera (C4742-98 ERG; Hamamatsu Photonics, Hamamatsu City, Japan). Light was provided by red and blue light emitting diodes (LEDs), with regulated total fluence rates. Luciferase activity was imaged every two hours for at least four days. Images were analyzed with ImagePro software (Media Cybernetics, Inc., Bethesda, MD, USA). Data were imported into the Biological Rhythms Analysis Software System (BRASS; http:/ /www. amillar.org) and analyzed with the FFT-NLLS (Fourier Transform-NonLinear Least Squares) suite of the program, as previously described [23]. Rhythms with a period between 15 and $35 \mathrm{~h}$ were taken to be within the circadian range.

\subsection{Leaf Movement Assays}

Plants were grown on a Murashige and Skoog (MS) medium supplemented with or without $2 \%$ sucrose in $14 \mathrm{~h}: 10 \mathrm{~h}$, light:dark $\left(100 \mu \mathrm{mol} \mathrm{m}^{-2} \mathrm{~s}^{-1}\right)$ for eight days before being transferred to 24-well cell culture plates (Greiner Labortechnik, Kremsmünster, Oberösterreich, Austria), one plant per well. The plates were put into continuous light at $23{ }^{\circ} \mathrm{C}$ or $28^{\circ} \mathrm{C}$. The light sources are described in the figure legends for each experiment. Leaf movements were recorded every $20 \mathrm{~min}$ for 5-7 days by Panasonic CCTV cameras, model WV-BP120 (Matsushita Communications Industrial, Yokohama, Japan). Post-run analysis was performed using the ImagePro software. Traces of the Y-coordinate position of leaves were imported into BRASS software. Two to three replicates were carried out for each experiment. The results of the replicates were similar and so were averaged.

\subsection{Sucrose Pulses}

Sucrose pulse experiments were carried out essentially as described in [16]. pifQ CCA1:LUC plants and wt CCA1:LUC plants were grown for 10 days in $14 \mathrm{~L}: 10 \mathrm{D} 100 \mu \mathrm{mol} \mathrm{m}^{-2} \mathrm{~s}^{-1}$ provided by white LEDs on MS media without sucrose on $0.8 \mu \mathrm{m}$ pore nylon mesh filters, in order to prevent the roots from penetrating into the media. The plants were transferred at dawn to $5 \mu \mathrm{mol} \mathrm{m}{ }^{-2} \mathrm{~s}^{-1}$ constant blue light (Bc), and luciferase activity was imaged at $1 \mathrm{~h}$ intervals. After $24 \mathrm{~h}$ in $\mathrm{Bc}$, the membranes with plants were transferred onto MS media supplemented with $3 \%$ sucrose and irrigated with liquid MS $+3 \%$ sucrose for a total of $3 \mathrm{~h}$. After the pulse, plants were washed with liquid MS media and transferred back onto MS plates for subsequent imaging. For the controls, the transfers were made using MS without sucrose. All the manipulations were done under green safe light. The time of the first peak after the sucrose pulse was determined using the BRASS "Peak time analysis" option.

\subsection{RNA Isolation and Analysis}

Ten to twelve seedlings were harvested per sample and total RNA extracted as previously described [24]. RNA samples were treated with DNase I (PerfeCTa DNAse from Quanta bio, Beverly, MA, USA) according to the manufacturer's instructions. From each DNA-free RNA sample, $5 \mu \mathrm{L}$ aliquots were used as a template to produce cDNA, using the qScript cDNA SuperMix (Quanta bio). $2.5 \mu \mathrm{L}$ of template cDNA was used for quantitative RT-PCR reaction with SYBR green reagent (KAPA SYBR FAST qPCR kit Master Mix, Kapa Biosystems, MA, USA) according to the supplier's protocol. Three technical repeats were made for each sample. Fluorescence was detected using the QuantStudio 12K Flex system (Thermo Fisher Scientific, MA, USA). PROTEIN PHOSPHATASE 2A (PP2A, AT1G13320), was used as a control for normalization [25]. Quantitation calculations were carried out using the 2- $\Delta \triangle \mathrm{CT}$ formula as described by [26]. The primers are shown in Supplementary Table S1. 


\section{Results}

3.1. Light-Dependent Roles for PHYTOCHROME INTERACTING FACTOR Regulation of Sucrose Signaling to the Oscillator

Our first goal was to determine whether and how blue light affected photosynthate regulation of the circadian oscillator. We grew pifQ and wt plants in Bc in the presence of $2 \%$ sucrose and examined the circadian rhythms of leaf movements. Figure 1a shows that, unlike under a wide range of fluences of constant red light (Rc) or in the dark (DD) [16], in Bc, the pifQ mutant did not show a long circadian period phenotype in the presence of sucrose. Expanding on this initial finding by analyzing LUC activity in pifQ CCA1:LUC and wt CCA1:LUC lines, we observed that, while pifQ CCA1:LUC plants grown on 3\% sucrose in Rc had longer periods (pifQ 24.4 \pm 0.07 ; wt $22.8 \pm 0.1$ ), plants growing in Bc had slightly but consistently shorter periods than wt CCA1:LUC (pifQ 22.1 \pm 0.03; wt 22.3 \pm 0.05 ; Figure 1b,c). Moreover, although increasing intensities of Bc caused a shorter period phenotype in both pifQ CCA1:LUC and wt CCA1:LUC lines in the presence of sucrose, there were only small differences between the responses of pifQ CCA1:LUC and wt CCA1:LUC (Figure 1d).

Since under natural conditions both the levels of sucrose derived from photosynthesis and the plant's sensitivity to photosynthates fluctuate during the course of the day, we examined the effects of treating pifQ CCA1:LUC and wt CCA1:LUC plants with a short pulse of sucrose in low Bc. Figure 1e shows that, by contrast, with the effect of sucrose pulses in Rc which caused a phase advance in wt plants [16], pulsing wt CCA1:LUC plants in Bc resulted in a phase delay, the first peak of CCA1:LUC occurred $24.9 \mathrm{~h}$ after the pulse, compared with $23.16 \mathrm{~h}$ for the non-pulsed control. However, like pulses in Rc, sucrose pulses in Bc did not significantly affect the circadian phase in pifQ CCA1:LUC plants under Bc (22.6 h after the pulse compared with $21.85 \mathrm{~h}$ for the non-pulsed control; $p=0.16$ Student two-tailed $t$-test).

The different effects of red and blue light on PIF-mediated sucrose regulation of the circadian oscillator (Figure 1) in [16] prompted us to examine how simultaneous irradiation with red and blue light affected sucrose signaling. Our results suggest that that even very low levels of red light $(1 \mu \mathrm{mol}$ $\mathrm{m}^{-2} \mathrm{~s}^{-1}$ ) partially reversed the blue light effects on the pifQ phenotype; with higher red-light intensities (more than $5 \mu \mathrm{mol} \mathrm{m} \mathrm{m}^{-2} \mathrm{~s}^{-1}$ ), pifQ CCA1:LUC plants showed a significantly longer period than wt CCA1:LUC (Figure 2). Moreover, under identical Rc conditions, the effect of pifQ on the period was affected by Bc levels; in $1 \mu \mathrm{mol} \mathrm{m} \mathrm{m}^{-2} \mathrm{~s}^{-1}$ red $+5 \mu \mathrm{mol} \mathrm{m} \mathrm{m}^{-2} \mathrm{~s}^{-1}$ blue (Rc/Bc is 1/5), pifQ CCA1:LUC plants had $0.52 \mathrm{~h}$ longer circadian periods than wt CCA1:LUC, but at Rc/Bc $1 / 60\left(1 \mu \mathrm{mol} \mathrm{m}^{-2} \mathrm{~s}^{-1} \mathrm{red}\right.$ $+60 \mu \mathrm{mol} \mathrm{m}{ }^{-2} \mathrm{~s}^{-1}$ blue), the difference in circadian period between wt CCA1:LUC and pifQ CCA1:LUC plants was much smaller $(0.1 \mathrm{~h}$, Figure $3 \mathrm{a})$. To determine whether the pifQ phenotype was dependent on total light fluence or the $\mathrm{Rc} / \mathrm{Bc}$ ratio, we examined plants under similar $\mathrm{Rc} / \mathrm{Bc}$ ratios but with different intensities. Figure $3 \mathrm{~b}$ shows that pifQ CCA1:LUC plants showed longer period phenotypes under both high and low total flux densities, suggesting that the ratio of $\mathrm{Rc} / \mathrm{Bc}$-rather than the total levels of Rc-may affect PIF-dependent entrainment of the oscillator in response to sucrose. This is consistent with the significant difference in period between wt CCA1:LUC and pifQ CCA1:LUC at similar (61 and $65 \mu \mathrm{mol} \mathrm{m} \mathrm{m}^{-2} \mathrm{~s}^{-1}$ ) fluences but different (Rc/Bc 1/60 and 1/12) Rc/Bc ratios (Figure 2). Together our results suggest that PIF mediation of photosynthate signaling to the circadian oscillator is light-quality-dependent. 
(a)

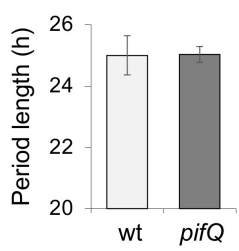

(d)

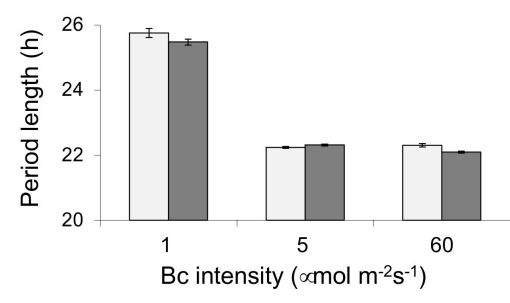

(b)

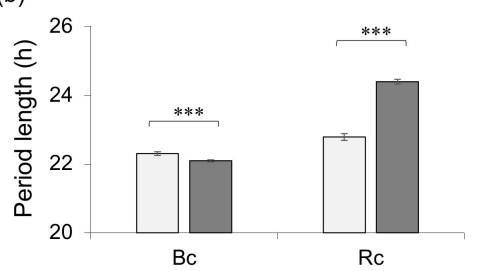

(c)

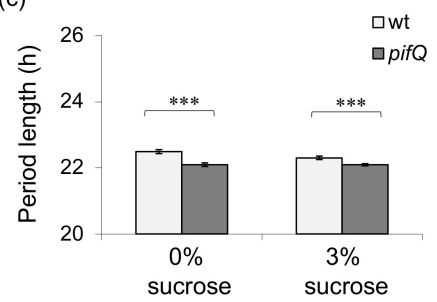

(e)

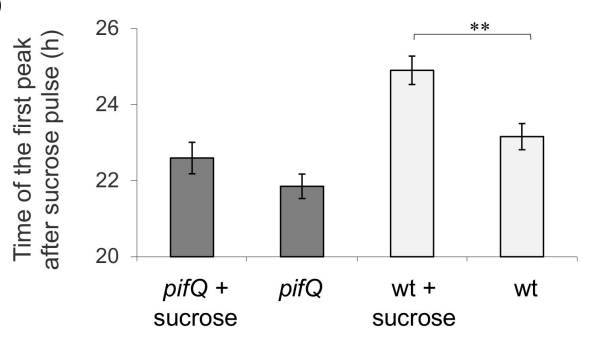

Figure 1. Blue and red light have different effects on PIF-mediated sucrose signaling. (a) The circadian period of leaf movements of wt and pifQ mutants grow on $2 \%$ sucrose containing medium for 8 days in $14 \mathrm{~h}$ : $10 \mathrm{~h}$, light: dark (white light, $100 \mu \mathrm{mol} \mathrm{m} \mathrm{m}^{-2} \mathrm{~s}^{-1}$ ) before being transferred to constant blue light (Bc) of $60 \mu \mathrm{mol} \mathrm{m}{ }^{-2} \mathrm{~s}^{-1}$. Average of 2 biological repeats, $n \geq 13$. (b-d) Luciferase activity of pifQ CCA1:LUC and wt CCA1:LUC plants grown for 8 days in $14 \mathrm{~h}: 10 \mathrm{~h}$, light: dark (white light, $100 \mu \mathrm{mol} \mathrm{m}{ }^{-2} \mathrm{~s}^{-1}$ ) on medium $(\mathbf{b}, \mathbf{d})$ with or (c) with and without $3 \%$ sucrose and transferred to either (b) Constant blue light (Bc) $\left(60 \mu \mathrm{mol} \mathrm{m}{ }^{-2} \mathrm{~s}^{-1}\right)$ and constant red light (Rc) $\left(50 \mu \mathrm{mol} \mathrm{m}{ }^{-2} \mathrm{~s}^{-1}\right)$ or (c) Bc $\left(60 \mu \mathrm{mol} \mathrm{m} \mathrm{m}^{-2} \mathrm{~s}^{-1}\right)$ or (d) Bc of different light intensities $\left(1,5,60 \mu \mathrm{mol} \mathrm{m} \mathrm{m}^{-2} \mathrm{~s}^{-1}\right)$. (e) Sucrose pulse experiments were performed as described in Materials and Methods. ${ }^{* *} p<0.01{ }^{* * *} p<0.001$ (Student two-tailed $t$-test). Average of (a) 2 biological repeats. $n \geq 106$, (b-d) 2-3 biological repeats. $n \geq 112$ (e) 3 biological repeats $n \geq 36$.

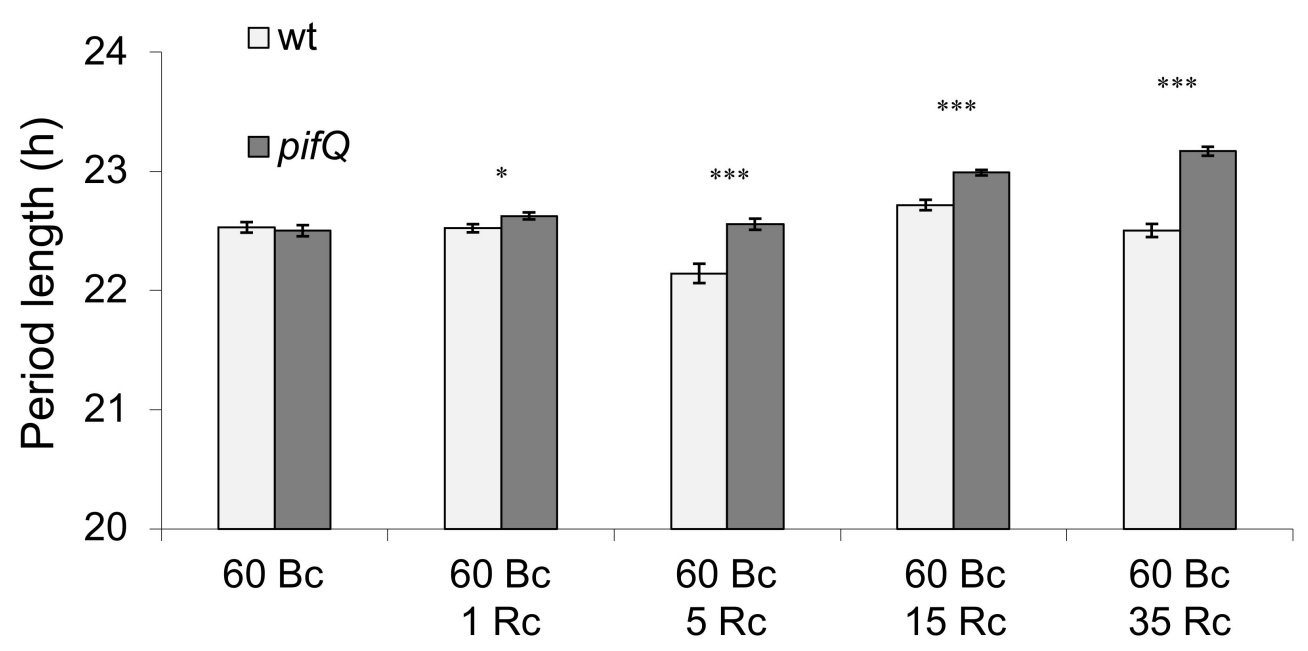

\section{$\mathrm{Bc}$ and Rc intensities ( $\propto \mathrm{cmol} \mathrm{m}^{-2} \mathrm{~s}^{-1}$ )}

Figure 2. Low levels of red light are sufficient to restore the long period pifQ phenotype. pifQ CCA1:LUC and wt CCA1:LUC lines were entrained for 8 days in $14 \mathrm{~h}$ : $10 \mathrm{~h}$, light: dark (white light, $100 \mu \mathrm{mol}$ $\mathrm{m}^{-2} \mathrm{~s}^{-1}$ ) on medium, supplemented with $3 \%$ sucrose before being transferred to different constant light conditions $\left(60 \mu \mathrm{mol} \mathrm{m}{ }^{-2} \mathrm{~s}^{-1} \mathrm{Bc}, 60 \mu \mathrm{mol} \mathrm{m} \mathrm{m}^{-2} \mathrm{~s}^{-1} \mathrm{Bc}+1 \mu \mathrm{mol} \mathrm{m} \mathrm{m}^{-2} \mathrm{~s}^{-1} \mathrm{Rc}, 60 \mu \mathrm{mol} \mathrm{m}^{-2} \mathrm{~s}^{-1}\right.$ $\mathrm{Bc}+5 \mu \mathrm{mol} \mathrm{m}{ }^{-2} \mathrm{~s}^{-1} \mathrm{Rc}, 60 \mu \mathrm{mol} \mathrm{m}{ }^{-2} \mathrm{~s}^{-1} \mathrm{Bc}+15 \mu \mathrm{mol} \mathrm{m}{ }^{-2} \mathrm{~s}^{-1} \mathrm{Rc}, 60 \mu \mathrm{mol} \mathrm{m}{ }^{-2} \mathrm{~s}^{-1} \mathrm{Bc}+35 \mu \mathrm{mol}$ $\mathrm{m}^{-2} \mathrm{~s}^{-1} \mathrm{Rc}$ ), and luciferase activity measured. Average of $2-4$ biological repeats. $\mathrm{n} \geq 103$. ${ }^{*} p<0.05$, *** $p<0.001$ (Student two-tailed $t$-test). 
(a)

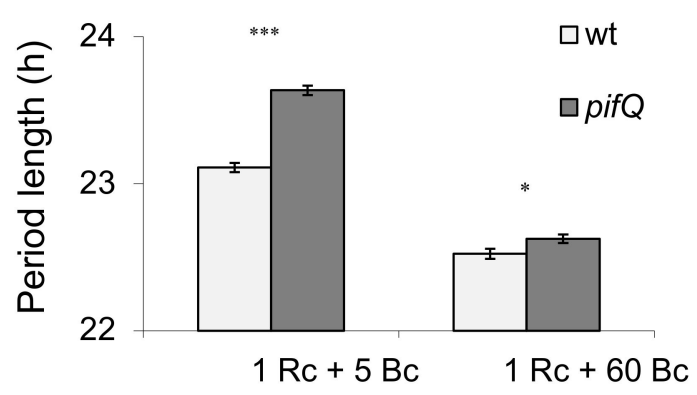

Bc and Rc intensities ( $\left.\circ \mathrm{mol} \mathrm{m} \mathrm{m}^{-2} \mathrm{~s}^{-1}\right)$ (b)

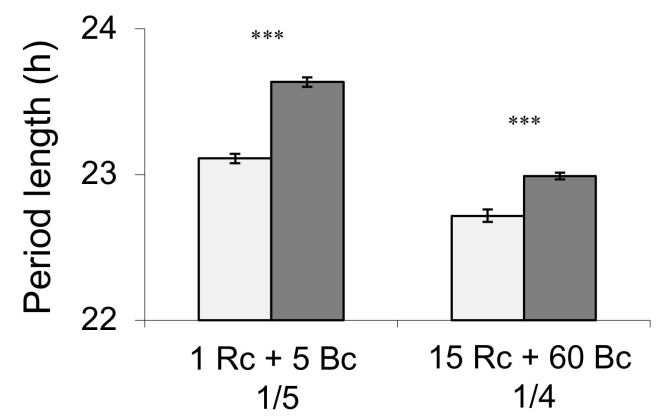

$\mathrm{Bc}$ and $\mathrm{Rc}$ intensities (omol m $\left.\mathrm{m}^{-2} \mathrm{~s}^{-1}\right)$ and ratio

Figure 3. The red/blue light ratio is important for PIF regulation of the circadian oscillator. pifQ CCA1:LUC and wt CCA1:LUC plants were entrained for 8 days in $14 \mathrm{~h}: 10 \mathrm{~h}$ white light: dark (white light, $100 \mu \mathrm{mol} \mathrm{m} \mathrm{m}^{-2} \mathrm{~s}^{-1}$ ) on medium supplemented with $3 \%$ sucrose before being transferred to different constant light conditions and luciferase activity measured. (a) Similar Rc light intensity and varied Rc/Bc ratio. (b) Similar Rc/Bc ratios and varied total light intensity. Average of 4 biological repeats. $\mathrm{n} \geq 213$. ${ }^{*} p<0.05,{ }^{* * *} p<0.001$ (Student two-tailed $t$-test).

\subsection{PHYTOCHROME INTERACTING FACTOR-Mediated Sucrose Signaling Is Temperature Dependent}

PHYTOCHROME INTERACTING FACTOR 4 is known to participate in temperature sensing by plants [27], and the circadian oscillator has been shown to gate (i.e., restrict to certain times of day) PIF4-mediated thermo-responses [28]. We examined whether temperature affected the PIF-mediated sucrose entrainment of the circadian oscillator. Figure 4 shows that pifQ plants have a more reduced period phenotype of both leaf movements and CCA1:LUC at $28^{\circ} \mathrm{C}$ than at $23^{\circ} \mathrm{C}$. pifQ mutants show a $1.3 \mathrm{~h}$ longer period of leaf movements than wt plants at $23^{\circ} \mathrm{C}$, compared with a $0.9 \mathrm{~h}$ longer period at $28^{\circ} \mathrm{C}$ (Figure $4 \mathrm{a}, \mathrm{C}$ ). The difference in CCA1:LUC period between pifQ and wt plants is $1.3 \mathrm{~h}$ at $23^{\circ} \mathrm{C}$ and $0.6 \mathrm{~h}$ at $28^{\circ} \mathrm{C}$ (Figure $4 \mathrm{~b}, \mathrm{~d}$ ). Our results suggest that PIFs have more of a role in the sucrose entrainment of the oscillator at lower temperatures.

Finally, to determine which PIF(s) participate in the temperature-dependent regulation of circadian rhythms, we analyzed individual PIF-overexpression lines (PIF-ox; Figure 5). In an RT-PCR analysis of PIF expression, each PIF-ox line showed that overexpression of individual PIFs did not have a significant effect on the levels of the other PIF genes examined (Supplementary Figure S1). Figure 5 shows that at $23{ }^{\circ} \mathrm{C}$, all the PIF-ox lines, except PIF4-ox, showed a shorter period of leaf movements. PIF4 overexpression did not significantly affect the circadian period at either $23{ }^{\circ} \mathrm{C}$ or $28^{\circ} \mathrm{C}\left(p=0.89\right.$ and $p=0.34$ for $23^{\circ} \mathrm{C}$ and $28^{\circ} \mathrm{C}$, respectively by Student two-tailed $t$-test). By contrast, overexpression of PIFs 1 and 5 affected periods at $23^{\circ} \mathrm{C}$, but not at $28{ }^{\circ} \mathrm{C}(p=0.79$ and $p=0.18$ for PIF5-ox and PIF1-ox, respectively by Student two-tailed $t$-test), while overexpression of PIF3 caused a statistically significantly shorter period circadian phenotype at both, $23^{\circ} \mathrm{C}$ and $28{ }^{\circ} \mathrm{C}$. Thus, PIFs 1 and 5 , but not PIF3, appear to have temperature-sensitive roles in the sucrose signal transduction to the circadian oscillator. 
(a)

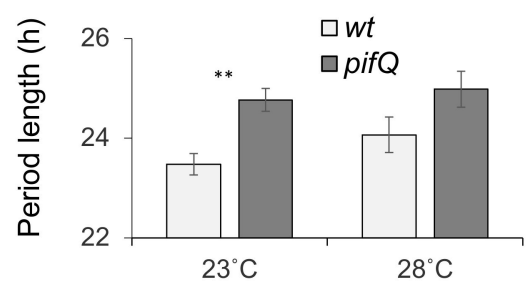

(b)

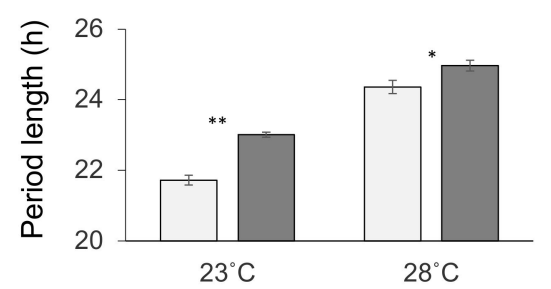

(c)

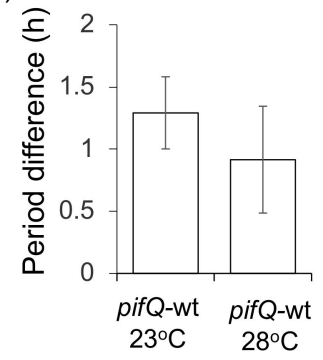

(d)

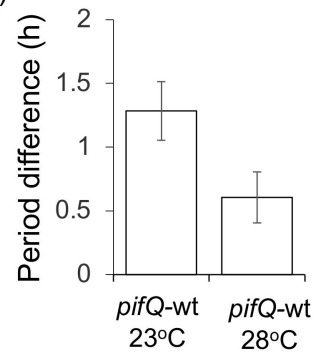

Figure 4. PIF-mediated sucrose signaling is temperature-sensitive. Circadian period of (a) leaf movements and (b) CCA1:LUC expression in wt plants and pifQ mutants, and differences in period length of plants at $23{ }^{\circ} \mathrm{C}$ and $28{ }^{\circ} \mathrm{C}$, measured by (c) leaf movements or by (d) CCA1:LUC luminescence. Plants growing on $(\mathbf{a}, \mathbf{c}) 2 \%$ sucrose or $(\mathbf{b}, \mathbf{d}) 3 \%$ sucrose containing medium were entrained for 8 days at $23{ }^{\circ} \mathrm{C}$ before being transferred to LL provided by mixed LEDs $(\mathbf{a}, \mathbf{c})$ red $\left(15 \mu \mathrm{mol} \mathrm{m} \mathrm{m}^{-2} \mathrm{~s}^{-2}\right)$ green $\left(10 \mu \mathrm{mol} \mathrm{m}{ }^{-2} \mathrm{~s}^{-2}\right)$ and blue $\left(25 \mu \mathrm{mol} \mathrm{m} \mathrm{m}^{-2} \mathrm{~s}^{-2}\right)$ or $(\mathbf{b}, \mathbf{d})$ red $\left(50 \mu \mathrm{molm}^{-2} \mathrm{~s}^{-2}\right)$ and blue $(60 \mu \mathrm{mol}$ $\mathrm{m}^{-2} \mathrm{~s}^{-2}$ ) at $23^{\circ} \mathrm{C}$ or $28^{\circ} \mathrm{C}$. Average of (a) 3 biological repeats, $\mathrm{n}=42-63$, (b) $2-3$ biological repeats, $\mathrm{n}=107-174 .{ }^{*} p<0.05,{ }^{* *} p<0.01$ (Student two-tailed $t$-test). (c,d) Period difference (pifQ-wt) plotted with the standard error of the mean (SEM) (c) $23{ }^{\circ} \mathrm{C} \mathrm{F}=11.1,28{ }^{\circ} \mathrm{C} \mathrm{F}=4.4$ (d) $23{ }^{\circ} \mathrm{C} \mathrm{F}=30.3,28{ }^{\circ} \mathrm{C}$ $F=8.94$ (two-way ANOVA temperature, genotype factors).

(a)

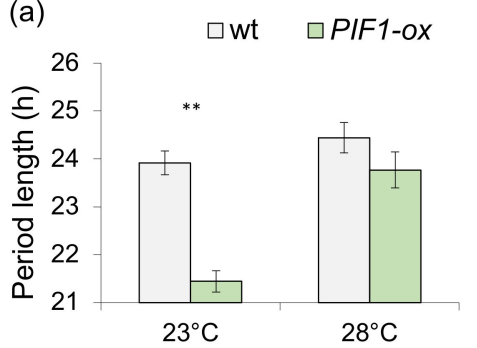

(c)

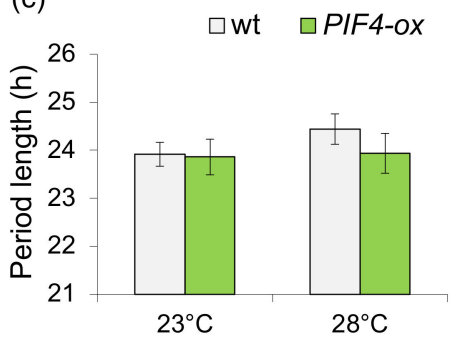

(b)

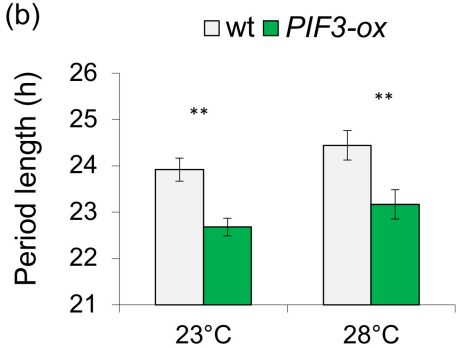

(d)

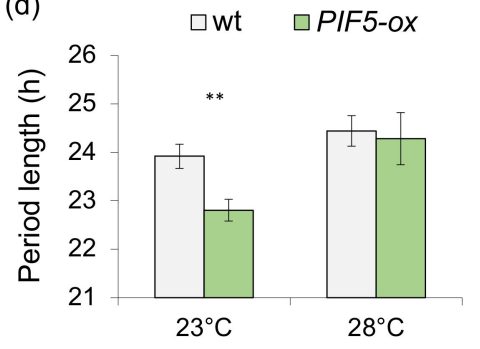

Figure 5. Circadian period of leaf movements of wt and PIF-overexpressing plants. Plants growing on $2 \%$ sucrose containing medium were entrained for 8 days at $14 \mathrm{~h}: 10 \mathrm{~h}$, light: dark $\left(100 \mu \mathrm{molm}^{-2} \mathrm{~s}^{-1}\right)$ at $23^{\circ} \mathrm{C}$ before being transferred to constant white light (provided by fluorescent lamps; $50 \mu \mathrm{mol} \mathrm{m}^{-2} \mathrm{~s}^{-1}$; colour temperature $6500 \mathrm{~K}$ ) at $23^{\circ} \mathrm{C}$ or $28^{\circ} \mathrm{C}$. (a) PIF1-ox, (b) PIF3-ox, (c) PIF4-ox, (d) PIF5-ox. Average of 2-3 biological repeats, $n=17-41$. ${ }^{* *} p<0.01$ (Student two-tailed $t$-test). 


\section{Discussion}

The results presented here show that, as in red light and in the dark, in blue light sucrose entrains the oscillator at dawn via PIF proteins. However, in contrast to red light, pifQ plants in blue light have a slightly but significantly shorter period (Figure 1). The levels of blue light required to inhibit sucrose-mediated entrainment are very low, comparable to those seen at the end of the night before sunrise [29]. Moreover, the red/blue ratio appears to affect PIF-mediated oscillator entrainment (Figures 2 and 3), although we cannot rule out effects of total light fluence on period. A potential ecological significance of the red/blue regulated sensitivity to sugar availability might be to enable plants to distinguish between sucrose produced de novo from photosynthesis during the day when red light levels are high and the sucrose products of starch degradation at the end of the night when blue lights levels are higher [30]. Thus, the sucrose state of plant and light quality signals may interact to optimize the timing of plant processes to match their environments.

These findings also suggest that signaling pathways regulating sucrose activity in the circadian system in red and blue light may be interconnected. Phys and Crys provide the circadian oscillator with sensitivity to light. Both, Cry1 and PhyA mediate low-intensity blue light for period length control [31]. Moreover, Cry1 is necessary for PhyA signaling. PhyA is also active under low red light, while PhyB is active under high red light. PhyB does not participate in the mediation of blue light signal to the clock. Cry1 and Cry2 act redundantly in blue light perception and participate in blue and red light input to the oscillator [31,32]. The mechanism by which blue light blocks the PIF-regulated sucrose entrainment of the oscillator may involve an altered sensitivity of PIFs 4 and 5 to blue light, via their direct interaction with the blue light photoreceptors, Cry1, and Cry2 [33,34]. As PIF4 and PIF5 also act downstream of Phys $[17,35]$, they may represent a molecular basis for the cross-talk between red/blue photosensory pathways. It is also possible that ZTL, FKF1, and LKP2, LOV-domain-based blue-light photoreceptors that regulate the circadian clock by controlling TOC1 and PRR5 stability [10,36-38], may be involved in the blue light regulation of PIF-mediated sucrose signal perception.

A number of temperature-dependent roles for PIF activity have been previously reported [17]. At high temperatures, wt but not pift plants show an altered morphology and reproductive development [27,39]. The expression of PIF4 and PIF5 is temperature regulated and is elevated in hypocotyls at high temperature [39]. PIF4 directly binds to the FT promoter in a temperature-dependent manner, leading to flowering induction at high temperatures [18]. PIF4 also regulates auxin biosynthesis and activity at high temperatures, resulting in increased levels of IAA in seedlings [40]. In the circadian system, temperature-dependent outputs of the oscillator are gated by PIF4 interactions with TOC1, resulting in the repression of warm-temperature activation of PIF4 target genes [28]. The functioning of the circadian system itself is, in turn, temperature-regulated. The expression of CCA1, LHY, TOC1, GI is affected by temperature conditions [41], and the temperature entrainment of the Arabidopsis circadian oscillator requires PRR3 and PRR7 [42]. During seed germination, sensitivity to daily temperature cycles is provided by PRR7 and TOC1, and the cyclic expression of PRR7 and TOC1 is stimulated by day/night temperature changes [43].

In this work we have shown that PIF-mediated sucrose signaling is also temperature-dependent (Figures 4 and 5); there is a smaller difference between the period lengths of pifQ mutants and wt plants at higher temperatures $\left(28^{\circ} \mathrm{C}\right.$ compared with $23^{\circ} \mathrm{C}$; Figure 4$)$. PIF1-ox and PIF5-ox are temperature-sensitive; overexpression effects circadian period at $23^{\circ} \mathrm{C}$, but not at $28^{\circ} \mathrm{C}$. By contrast, PIF3-ox affects period phenotype in both high and low temperatures. Overexpression of PIF4 did not significantly affect temperature sensitivity of the circadian period (Figure 5), possibly as a result of increased levels of PIF4 in wt plants at high temperatures [44], resulting in wt and PIF4-ox plants having similar levels of PIF4 under these conditions. Together with the discovery that pif 34 , but not pif13 double mutants or pif3 single mutants, have long period circadian phenotype [16,45], these data indicate that it is the presence and not the quantity of PIF4 that is most important for clock regulation.

In summary, the work described here demonstrates that the PIF-mediated entrainment of the Arabidopsis circadian oscillator by sugars is temperature- and light quality-dependent. PIFs act as a hub 
for environmental factors in the regulation of the clock. This finding gives us a deeper understanding of how the plants adapt their circadian systems to the environment, utilizing multiple signals-light, temperature and sucrose levels-to accurately determine the time of day.

Supplementary Materials: The following are available online at http:/ /www.mdpi.com/2073-4425/9/12/628/s1, Figure S1: The effects of PIF-overexpression on levels of individual PIFs. Table S1: Primers, used for RT-PCR.

Author Contributions: E.S., A.K. and R.P. carried out the experiments. E.S., A.K., R.P. and I.P, contributed to the interpretation of the results and edited the manuscript, I.P. and E.H. contributed experimental tools, R.G. and E.S. devised the experiments and prepared the manuscript, E.H. commented on the manuscript.

Funding: This research was funded by the United States Israel Bilateral Science Foundation (2015316) to R.G. and E.H. and the Ministry of Absorption to E.S.

Conflicts of Interest: The authors declare no conflicts of interest.

\section{References}

1. Alabadi, D.; Oyama, T.; Yanovsky, M.J.; Harmon, F.G.; Mas, P.; Kay, S.A. Reciprocal regulation between TOC1 and LHY/CCA1 within the Arabidopsis circadian clock. Science 2001, 293, 880-883. [CrossRef] [PubMed]

2. Hsu, P.Y.; Harmer, S.L. Wheels within wheels: The plant circadian system. Trends Plant Sci. 2014, 19, 240-249. [CrossRef] [PubMed]

3. Greenham, K.; McClung, C.R. Integrating circadian dynamics with physiological processes in plants. Nat. Rev. Genet. 2015, 16, 598-610. [CrossRef] [PubMed]

4. Más, P. Circadian clock function in Arabidopsis thaliana: Time beyond transcription. Trends Cell Biol. 2008, 18, 273-281. [CrossRef] [PubMed]

5. Gray, J.A.; Shalit-Kaneh, A.; Chu, D.N.; Hsu, P.Y.; Harmer, S.L. The REVEILLE clock genes inhibit growth of juvenile and adult plants by control of cell size. Plant Physiol. 2017, 173, 2308-2322. [CrossRef]

6. Nolte, C.; Staiger, D. RNA around the clock-Regulation at the RNA level in biological timing. Front. Plant Sci. 2015, 6, 311. [CrossRef]

7. Romanowski, A.; Yanovsky, M.J. Circadian rhythms and post-transcriptional regulation in higher plants. Front. Plant Sci. 2015, 6, 437. [CrossRef]

8. Yakir, E.; Hilman, D.; Hassidim, M.; Green, R.M. CIRCADIAN CLOCK ASSOCIATED1 transcript stability and the entrainment of the circadian clock in Arabidopsis. Plant Physiol. 2007, 145, 925-932. [CrossRef]

9. Más, P.; Kim, W.Y.; Somers, D.E.; Kay, S.A. Targeted degradation of TOC1 by ZTL modulates circadian function in Arabidopsis thaliana. Nature. 2003, 426, 567-570. [CrossRef]

10. Baudry, A.; Ito, S.; Song, Y.H.; Strait, A.A.; Kiba, T.; Lu, S.; Henriques, R.; Pruneda-Paz, J.L.; Chua, N.H.; Tobin, E.M.; et al. F-box proteins FKF1 and LKP2 act in concert with ZEITLUPE to control Arabidopsis clock progression. Plant Cell. 2010, 22, 606-622. [CrossRef]

11. Yakir, E.; Hilman, D.; Harir, Y.; Green, R.M. Regulation of output from the plant circadian clock. FEBS J. 2007, 274, 335-345. [CrossRef] [PubMed]

12. Knight, H.; Thomson, A.J.; McWatters, H.G. SENSITIVE TO FREEZING6 integrates cellular and environmental inputs to the plant circadian clock. Plant Physiol. 2008, 148, 293-303. [CrossRef]

13. Haydon, M.J.; Mielczarek, O.; Robertson, F.C.; Hubbard, K.E.; Webb, A.A. Photosynthetic entrainment of the Arabidopsis thaliana circadian clock. Nature 2013, 502, 689-692. [CrossRef] [PubMed]

14. Haydon, M.J.; Mielczarek, O.; Frank, A.; Román, Á.; Webb, A.A. Sucrose and ethylene signaling interact to modulate the circadian clock. Plant Physiol. 2017, 175, 947-958. [CrossRef]

15. Frank, A.; Matiolli, C.C.; Viana, A.J.C.; Hearn, T.H.; Kusakina, J.; Belbin, F.E.; Newman, D.W.; Yochikawa, A.; Cano-Ramirez, D.L.; Chembath, A.; et al. Circadian entrainment in Arabidopsis by the sugar-responsive transcription factor bZIP63. Curr. Biol. 2018, 28, 2597-2606. [CrossRef]

16. Shor, E.; Paik, I.; Kangisser, S.; Green, R.; Huq, E. Phytochrome Interacting Factors mediate metabolic control of the circadian system in Arabidopsis. New Phytol. 2017, 215, 217-228. [CrossRef] [PubMed]

17. Paik, I.; Kathare, P.K.; Kim, J.-I.; Huq, E. Expanding roles of PIFs in signal integration from multiple processes. Mol. Plant 2017, 10, 1035-1046. [CrossRef]

18. Kumar, S.V.; Lucyshyn, D.; Jaeger, K.E.; Alós, E.; Alvey, E.; Harberd, N.P.; Wigge, P.A. Transcription factor PIF4 controls the thermosensory activation of flowering. Nature 2012, 484, 242-245. [CrossRef] 
19. Leivar, P.; Monte, E.; Oka, Y.; Liu, T.; Carle, C.; Castillon, A.; Huq, E.; Quail, P.H. Multiple phytochrome-interacting bHLH transcription factors repress premature seedling photomorphogenesis in darkness. Curr. Biol. 2008, 18, 1815-1823. [CrossRef]

20. Zhu, L.; Bu, Q.; Xu, X.; Paik, I.; Huang, X.; Hoecker, U.; Deng, X.W.; Huq, E. CUL4 forms an E3 ligase with COP1 and SPA to promote light-induced degradation of PIF1. Nat. Commun. 2015, 6, 7245. [CrossRef]

21. Park, E.; Kim, J.; Lee, Y.; Shin, J.; Oh, E.; Chung, W.I.; Liu, J.R.; Choi, G. Degradation of phytochrome interacting factor 3 in phytochrome-mediated light signaling. Plant Cell Physiol. 2004, 45, 968-975. [CrossRef] [PubMed]

22. Sakuraba, Y.; Jeong, J.; Kang, M.Y.; Kim, J.; Paek, N.C.; Choi, G. Phytochrome-interacting transcription factors PIF4 and PIF5 induce leaf senescence in Arabidopsis. Nat. Commun. 2014, 5, 4636. [CrossRef] [PubMed]

23. Plautz, J.D.; Straume, M.; Stanewsky, R.; Jamison, C.F.; Brandes, C.; Dowse, H.B.; Hall, J.C.; Kay, S.A. Quantitative analysis of Drosophila period gene transcription in living animals. J. Biol. Rhythm. 1997, 12, 204-217. [CrossRef] [PubMed]

24. Green, R.M.; Tobin, E.M. Loss of the circadian clock-associated protein 1 in Arabidopsis results in altered clock-regulated gene expression. Proc. Natl. Acad. Sci. USA 1999, 96, 4176-4179. [CrossRef] [PubMed]

25. Czechowski, T.; Stitt, M.; Altmann, T.; Udvardi, M.K.; Scheible, W.R. Genome-wide identification and testing of superior reference genes for transcript normalization in Arabidopsis. Plant Physiol. 2005, 139, 5-17. [CrossRef] [PubMed]

26. Nozue, K.; Covington, M.F.; Duek, P.D.; Lorrain, S.; Fankhauser, C.; Harmer, S.L.; Maloof, J.N. Rhythmic growth explained by coincidence between internal and external cues. Nature 2007, 448, 358-361. [CrossRef] [PubMed]

27. Koini, M.A.; Alvey, L.; Allen, T.; Tilley, C.A.; Harberd, N.P.; Whitelam, G.C.; Franklin, K.A. High temperaturemediated adaptations in plant architecture require the bHLH transcription factor PIF4. Curr. Biol. 2009, 19, 408-413. [CrossRef]

28. Zhu, J.Y.; Oh, E.; Wang, T.; Wang, Z.Y. TOC1-PIF4 interaction mediates the circadian gating of thermoresponsive growth in Arabidopsis. Nat Commun. 2016, 7, 13692. [CrossRef]

29. Spitschan, M.; Aguirre, G.K.; Brainard, D.H.; Sweeney, A.M. Variation of outdoor illumination as a function of solar elevation and light pollution. Sci. Rep. 2016, 6, 26756. [CrossRef]

30. Smith, A.M.; Zeeman, S.C.; Smith, S.M. Starch degradation. Annu. Rev. Plant Biol. 2005, 56, 73-98. [CrossRef]

31. Devlin, P.F.; Kay, S.A. Cryptochromes are required for phytochrome signaling to the circadian clock but not for rhythmicity. Plant Cell 2000, 12, 2499-2510. [CrossRef] [PubMed]

32. Somers, D.E.; Devlin, P.F.; Kay, S.A. Phytochromes and cryptochromes in the entrainment of the Arabidopsis circadian clock. Science 1998, 282, 1488-1490. [CrossRef] [PubMed]

33. Pedmale, U.V.; Huang, S.S.; Zander, M.; Cole, B.J.; Hetzel, J.; Ljung, K.; Reis, P.A.; Sridevi, P.; Nito, K.; Nery, J.R.; et al. Cryptochromes Interact Directly with PIFs to Control Plant Growth in Limiting Blue Light. Cell 2016, 164, 233-245. [CrossRef] [PubMed]

34. Ma, D.; Li, X.; Guo, Y.; Chu, J.; Fang, S.; Yan, C.; Noel, J.P.; Liu, H. Cryptochrome 1 interacts with PIF4 to regulate high temperature-mediated hypocotyl elongation in response to blue light. Proc. Natl. Acad. Sci. USA 2016, 113, 224-229. [CrossRef] [PubMed]

35. Leivar, P.; Monte, E. PIFs: Systems integrators in plant development. Plant Cell 2014, 26, 56-78. [CrossRef] [PubMed]

36. Sawa, M.; Nusinow, D.A.; Kay, S.A.; Imaizumi, T. FKF1 and GIGANTEA complex formation is required for day-length measurement in Arabidopsis. Science 2007, 318, 261-265. [CrossRef] [PubMed]

37. Kim, W.Y.; Fujiwara, S.; Suh, S.S.; Kim, J.; Kim, Y.; Han, L.; David, K.; Putterill, J.; Nam, H.G.; Somers, D.E. ZEITLUPE is a circadian photoreceptor stabilized by GIGANTEA in blue light. Nature 2007, 449, 356-360. [CrossRef]

38. Kim, J.; Geng, R.; Gallenstein, R.A.; Somers, D.E. The F-box protein ZEITLUPE controls stability and nucleocytoplasmic partitioning of GIGANTEA. Development 2013, 140, 4060-4069. [CrossRef]

39. Stavang, J.A.; Gallego-Bartolome, J.; Gomez, M.D.; Yoshida, S.; Asami, T.; Olsen, J.E.; Garcia-Martinez, J.L.; Alabadi, D.; Blazquez, M.A. Hormonal regulation of temperature-induced growth in Arabidopsis. Plant J. 2009, 60, 589-601. [CrossRef] 
40. Franklin, K.A.; Lee, S.H.; Patel, D.; Kumar, S.V.; Spartz, A.K.; Gu, C.; Ye, S.; Yu, P.; Breen, G.; Cohen, J.D.; et al. PHYTOCHROME-INTERACTING FACTOR 4 (PIF4) regulates auxin biosynthesis at high temperature. Proc. Natl. Acad. Sci. USA 2011, 108, 20231-20235. [CrossRef]

41. Gould, P.D.; Locke, J.C.; Larue, C.; Southern, M.M.; Davis, S.J.; Hanano, S.; Moyle, R.; Milich, R.; Putterill, J.; Millar, A.J.; et al. The molecular basis of temperature compensation in the Arabidopsis circadian clock. Plant Cell 2006, 18, 1177-1187. [CrossRef] [PubMed]

42. Salomé, P.A.; McClung, C.R. PSEUDO-RESPONSE REGULATOR 7 and 9 are partially redundant genes essential for the temperature responsiveness of the Arabidopsis circadian clock. Plant Cell 2005, 17, 791-803. [CrossRef] [PubMed]

43. Arana, M.V.; Tognacca, R.S.; Estravis-Barcalá, M.; Sánchez, R.A.; Botto, J.F. Physiological and molecular mechanisms underlying the integration of light and temperature cues in Arabidopsis thaliana seeds. Plant Cell Environ. 2017, 40, 3113-3121. [CrossRef] [PubMed]

44. Sun, J.; Qi, L.; Li, Y.; Chu, J.; Li, C. PIF4-mediated activation of YUCCA8 expression integrates temperature into the auxin pathway in regulating Arabidopsis hypocotyl growth. PLoS Genet. 2012, 8, e1002594. [CrossRef] [PubMed]

45. Viczian, A.; Kircher, S.; Fejes, E.; Millar, A.J.; Schafer, E.; Kozma-Bognar, L.; Nagy, F. Functional characterization of phytochrome interacting factor 3 for the Arabidopsis thaliana circadian clockwork. Plant Cell Physiol. 2005, 46, 1591-1602. [CrossRef] [PubMed]

(C) 2018 by the authors. Licensee MDPI, Basel, Switzerland. This article is an open access article distributed under the terms and conditions of the Creative Commons Attribution (CC BY) license (http:/ / creativecommons.org/licenses/by/4.0/). 